\title{
Síndrome de Dravet
}

\author{
M. ${ }^{a}$ Mercedes Mingarro Castilloa , Javier Carmona de la Morenaa,b, Paz Latre Martínezª,c \\ y Luis Miguel Aras Portilla $a^{\mathrm{a}, \mathrm{d}, \mathrm{e}}$
}

\begin{abstract}
a Grupo de Trabajo de Genética Clínica y Enfermedades Raras. Sociedad Española de Medicina Familiar y Comunitaria.

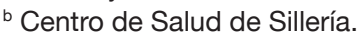
Toledo (España).

${ }^{c}$ Centro de Salud San José Centro. Zaragoza (España). a Director de investigación. Fundación Síndrome de Dravet. e SNU Estella. Servicio Navarro de Salud (España).
\end{abstract}

\section{Correspondencia:}

M. ${ }^{\text {a }}$ Mercedes Mingarro Castillo. Correo electrónico: merchemingarro@yahoo.es

Recibido el 29 de enero de 2014.

Aceptado para su publicación el 11 de febrero de 2014.

\begin{abstract}
RESUMEN
El síndrome de Dravet es una forma severa de epilepsia, de origen genético, que se inicia en la infancia. Además, se observa retraso en el desarrollo cognitivo y problemas en el aprendizaje, coordinación de movimientos y en la conducta. La paciente es una niña de 8 años de edad que a los 4 meses presentó una convulsión tónico-clónica tras vacunación y fiebre. El estudio fue normal, pero al persistir las crisis se inició terapia con fármacos bloqueadores del sodio que empeoraron la enfermedad. Se solicitó el test genético que fue positivo para SCN1A y que la Fundación Dravet ofrece gratuitamente. Actualmente sufre un trastorno mental leve y persisten las convulsiones, a pesar del tratamiento con ácido valproico, topiramato, clobazam y stiripentol.
\end{abstract}

Palabras clave: Epilepsia. Enfermedades Raras. Genética Médica. Trastornos cognitivos.

\begin{abstract}
Dravet syndrome

Dravet Syndrome is a severe type of epilepsy, genetic in origin, which presents in childhood. Produces delay in cognitive development as well as learning, coordination of movements and behavior disabilities. Our patient is an eigth year old child who at 4 months of age presented with tonic-clonic seizure following vaccination and fever. The assessment was normal but due to persisting crisis, drug therapy with sodium channel blockers was administered. This worsened the disease. A genetic study, that Dravet Foundation provides free of charge, turned up positive for SCN1A. At present, the girl suffers a mild mental disorder, and seizures persist despite treatment with valproic acid, topiramate, clobazam and stiripentol.
\end{abstract}

Key words: Epilepsy. Rare Diseases. Genetics, Medical. Cognition Disorders.

\section{INTRODUCCIÓN}

El síndrome de Dravet es una forma severa de epilepsia, de origen genético, que se inicia en la más temprana infancia, generalmente antes del primer año de edad, y se caracteriza por la presencia de diferentes tipos de crisis convulsivas, en ocasiones desencadenadas por diferentes estímulos como la fiebre ${ }^{1}$. A partir de los dos años de edad se observan retrasos evidentes en el desarrollo cognitivo, así como problemas en el aprendizaje, coordinación de movimientos y en la conducta. En un $60 \%$ de las ocasiones se acompaña de retraso mental severo. Además se asocia a otras patologías: cardiovasculares, alteraciones dentales, deformaciones de la columna vertebral, trastornos del sueño, etc., y produce una muerte prematura en alrededor del $15 \%$ de los casos. En el adolescente y el adulto cobran mayor importancia las alteraciones del comportamiento (hiperactividad y trastornos de la atención y, con menor frecuencia, rasgos de espectro autismo) y los trastornos del sueño ${ }^{2,3}$.

El síndrome de Dravet se considera una enfermedad rara cuya incidencia es de $1 / 20.000$ a $1 / 40.000$ nacidos vivos y cuya prevalencia es del $7 \%$ de las epilepsias en menores de 3 años. Afecta a varones y mujeres por igual y se da en todo el mundo. 
Existen más de 500 diferentes tipos de mutaciones descritas. Existen mutaciones en el gen SCN1A, localizado en el cromosoma 2, en un 70-80 \% de los pacientes; dicho gen codifica la subunidad alfa 1 de los canales de sodio dependientes de voltaje nav 1.1 , y cuyo correcto funcionamiento es imprescindible para la transmisión del impulso nervioso entre las neuronas ${ }^{4,5}$. Por tanto, podemos considerar al síndrome de Dravet una canalopatía. En el 90 $\%$ de las ocasiones la mutación es de novo, pero incluso en estas ocasiones se recomienda consejo genético debido al mosaicismo existente.

La pérdida de función de los canales nav 1.1 incide fundamentalmente en la capacidad de generar potencial de acción en las neuronas inhibitorias gabaergicas, provocando una alteración en el correcto balance excitación-inhibicion ${ }^{6}$.

\section{OBSERVACIONES CLÍNICAS}

La paciente, niña de 8 años de edad, presentó a los 4 meses una convulsión tónico-clónica tras vacunación acompañándose de febrícula de $37,5^{\circ} \mathrm{C}$. El estudio realizado con electroencefalograma (EEG), ecografía cerebral y analítica fue normal y se diagnosticó como convulsión febril. Dos semanas después presentó otra convulsión similar con febrícula y tres meses después presentó dos episodios de ausencias y una crisis convulsiva a las 24 horas. En esta ocasión el estudio con EEG, resonancia magnética nuclear y analítica fue normal y se inició terapia con ácido valproico. Al persistir las crisis, se añadió oxcarbazepina, que provocó un status epilepticus. Por ello se retiró este último y se pautó topiramato junto al ácido valproico, ante la sospecha clínica de epilepsia generalizada convulsiones febriles plus. Hasta los 2 años de edad presentó más de 20 episodios convulsivos tónico-clónicos, a veces hemilaterales, y mioclonías ocasionales que se hicieron diarias a partir de los 2 años. Las mioclonías diarias se acompañaron de alteraciones típicas en el EEG: paroxismos de punta de onda y polipunta generalizada. Se añadió clobazam, que redujo el número de crisis. Además, presentaba alteraciones frecuentes del sueño con múltiples despertares. Se solicitó el test genético, que fue positivo para SCN1A. A los tres años de edad, por la persistencia de mioclonías diarias e intolerancia al calor, se sustituyó el topiramato por stiripentol. Disminuyeron las mioclonías, pero aparecieron crisis tónico-clónicas afebriles. Además presentaba hiperactividad y trastornos de la atención y se diagnosticó retraso mental leve. Desde los 5 años presenta fotosensibilidad extrema y mioclonías secundarias a patrones geométricos que limitan su salida al exterior. Actualmente persisten las convulsiones febriles y afebriles y mioclonías aisladas a pesar del tratamiento con ácido valproico, topiramato, clobazam y stiripentol, pero presenta mejora de la atención, mejora cognitiva, sobre todo en el área verbal, y del estado general. El seguimiento se lleva a cabo en el servicio de Neuropediatría hospitalaria en colaboración con el equipo de Pediatría de Atención Primaria.

\section{COMENTARIOS}

Las crisis convulsivas suelen desencadenarse por la presencia de fiebre, tras vacunación o sin fiebre. Existen diferentes tipos: tónico-clónicas, mioclónicas, ausencias y crisis parciales complejas. Las crisis mioclónicas son las más características, aunque no imprescindibles, y consisten en una pérdida de conciencia y convulsiones generalizadas o unilaterales. En general, las crisis aparecen con cierta periodicidad, cada 6-8 semanas, y entre el primer y cuarto año de vida aparecen más frecuentemente y sin tanta relación con la fiebre. Si duran más de media hora se trata de un status epilepticus, complicación más grave. Otros estímulos desencadenantes son la luz artificial (televisión, ordenador), el sol, cambios de temperatura, esfuerzos físicos o excitación.

La mayoría de los pacientes sufren un retraso del desarrollo y problemas de aprendizaje que afectan al lenguaje y, por lo tanto, a la comunicación, y que evolucionan a un déficit intelectual, a menudo severo y que se estabiliza a partir de los 4 años. Los problemas de comportamiento dificultan, a su vez, el aprendizaje y la vida cotidiana del niño y su familia. Con el tiempo aparecen problemas de coordinación que dificultan la marcha y los movimientos finos.

El síndrome de Dravet es una enfermedad infradiagnosticada por su semejanza con otros síndromes epilépticos a pesar de la existencia de criterios de sospecha. Muchos de los fármacos de primera elección en la epilepsia (bloqueadores del sodio) están contraindicados en el síndrome de Dravet, dado que empeoran el déficit de función de los canales de sodio nav 1.1 y provocan status epilépticus y empeoramiento del curso de la enfermedad. De ahí la importancia del diagnóstico precoz. Existe un test genético caro, pero actualmente la Fundación Dravet lo ofrece gratuitamente a cual- 
quier paciente del mundo. Detecta la anomalía en el gen SCN1A en una muestra de sangre del niño. No permite establecer el diagnóstico, sino que lo confirma en determinados casos: niño que presenta su primera crisis convulsiva antes de los 12 meses y cuya historia clínica revela crisis frecuentes, largas (>10 minutos) o status epilepticus ( $>30 \mathrm{mi}-$ nutos), que requieren varios fármacos para un control aceptable, cuyo patrón cambia con la edad e incluye crisis hemiclónicas, focales y mioclónicas, que se desencadenan con moderada elevación de la temperatura, tras la vacunación y al someterse a la luz, que muestran un desarrollo inicial normal con EEG y estudios metabólicos normales y que presentan problemas del desarrollo y ataxia a partir del segundo año de vida.

No existe un tratamiento curativo, pues es fármaco-resistente, pero es posible disminuir el riesgo de aparición del status epilepticus, frenando así la progresión de la enfermedad, con la combinación de valproato, clobazam y stiripentol, fármacos no exentos de efectos adversos importantes. Para favorecer el desarrollo de la capacidad motora e intelectual existen diferentes métodos de estimulación. Se aconseja evitar la exposición del niño a posibles desencadenantes de las crisis. La familia necesita la intervención de un psicólogo para sobrellevar el estrés y el cuidado del niño. El seguimiento requiere de un neuropediatra en un servicio de epilepsia y la colaboración del médico de familia.

\section{BIBLIOGRAFÍA}

1. Wolff M, Cassé-Perrot C, Dravet C. Severe myoclonic epilepsy of infants (Dravet syndrome): natural history and neuropsychological findings. Epilepsia. 2006; 47 Suppl. 2: 45-8.

2. Genton P, Velizarova R, Dravet C. Dravet syndrome: The long-term outcome. Epilepsia. 2011; 52 Suppl. 2: 44-9.

3. Brunklaus A, Dorris L, Zuberi SM. Comorbidities and predictors of health-related quality of life in Dravet syndrome. Epilepsia. 2011; 52: 1476-82.

4. Claes L, Del-Favero J, Ceulemans B, Lagae L, Van Broeckhoven $\mathrm{C}$, De Jonghe P. De novo mutations in the sodiumchannel gene SCN1A cause severe myoclonic epilepsy of infancy. Am J Hum Genet. 2001; 68 (6): 1327-32.

5. Catterall WA. From ionic currents to molecular mechanisms: the structure and function of voltage-gated sodium channels. Neuron. 2000; 26 (1): 13-25.

6. Ogiwara I,Miyamoto H, Morita N, Atapour N, Mazaki E, Inoue I et al. Nav 1.1. localizes to axons of parvalbuminpositive inhibitory interneurons: a circuit basis for epileptic seizures in mice carrying an Scn1a gene mutation. J Neurosci. 2007; 27 (22): 5903-14. 